\title{
Determinants on Levels of Nursing Faculty Support Towards Student Nurse Midwives Performance During Midwifery Clinical Practice
}

\author{
Millicent Gatwiri Kabiru ${ }^{1, ~ *}$, Blasio Osogo Omuga ${ }^{2}$, Leila Geteri ${ }^{3}$, Taratisio Ndwiga ${ }^{4}$ \\ ${ }^{1}$ Faculty of Clinical Sciences, Kenya Medical Training College, Nairobi, Kenya \\ ${ }^{2}$ School of Nursing Sciences, Nairobi University, Nairobi, Kenya \\ ${ }^{3}$ Faculty of Community Health, Great Lakes University, Kisumu, Kenya \\ ${ }^{4}$ School of Public Health, Moi University, Eldoret, Kenya \\ Email address: \\ gatwiri.millicent@yahoo.com (M. G. Kabiru),mitega@yahoo.com (B. O. Omuga), leilageteri@gmail.com (L. Geteri), \\ taratisiondwiga@gmai.com (T. Ndwiga) \\ *Corresponding author
}

\section{To cite this article:}

Millicent Gatwiri Kabiru, Blasio Osogo Omuga, Leila Geteri, Taratisio Ndwiga. Determinants on Levels of Nursing Faculty Support Towards Student Nurse Midwives Performance During Midwifery Clinical Practice. Central African Journal of Public Health. Vol. 5, No. 5, 2019, pp. 190-197. doi: 10.11648/j.cajph.20190505.12

Received: June 24, 2019; Accepted: August 4, 2019; Published: August 19, 2019

\begin{abstract}
Background: This study focused on the midwifery clinical practice for student nurse midwives at Kenya medical training college and its constituent's colleges. Chi square was used to establish the relationship between demographic factors, institutional support and social cultural factors, which correlated with midwifery clinical practice performance, for student nurse midwives during clinical training. Methodology; Mixed method was adopted where 300 final year Kenya registered community nurse students were randomly selected from 8 nursing campuses. Data was collected using a pretested, self-administered questionnaire, Focused group discussions from students, elicited the qualitative data. Ethical approval was granted by Great Lakes University of Kisumu ethical review committee and the Kenya Medical Training College Institutional Research Committee. Results; Data was analyzed using SPSS version 19 and presented using descriptive and inferential statistics whereby logistical regression was used to compare the outcomes. Qualitative data was transcribed into themes for comparison with quantitative statistical findings. The study identified crucial determinants of student nurse midwives performance, during midwifery clinical practice. This study found that there was significant relationship between good institutional support and clinical practice performance, in clinical assessments and progress report scores. Strong social cultural influence, was significantly related to clinical practice performance with those with strong influence, performing poorer than those that had weak influence [OR $0.48,95 \%$ CI $0.26-0.89, p=0.02$ ]. However, demographic characteristics were not significantly related to performance in this particular study. Conclusion; The study concludes that faculty and clinical practice environment support was significant to good clinical practice performance and a good consideration in student nurse midwives training. Social cultural factors should be considered when training midwives, considering the sensitivity, of reproductive health issues among different communities in Kenya. Recommendation; The study recommends that nursing and midwifery faculties should enhance policies for lecturers and clinical instructors to teach and guide students during clinical practice. Social cultural issues should be addressed at training level, to optimize clinical practice performance and institutional support during student clinical practice.
\end{abstract}

Keywords: Performance, Clinical Practice, Midwifery, Student Midwives, Clinical Instructors, Nursing and Midwifery Faculties 


\section{Introduction}

The scope of Nursing and midwifery education globally and in Kenya aims at developing, individual student nurse midwives to become critical thinkers, analytical and interpret scientific data for midwifery, nursing actions, problem solving and exercise independent clinical judgment for woman, their families and community [1]. The nursing diploma course at Kenya medical training college is a three and half years integrated programme. The student nurse midwives are required to undertake a total midwifery clinical practice of 36 weeks, during which they are expected to gain clinical experience, and finally be assessed on the practical assessments, to ascertain whether they have gained the necessary skills and competences, which make value judgment of their performance before they can be released to the job market [2].

Kenya Medical Training College is a state autonomous government agency that trains health professionals, that are competent and community sensitive to provide care when and where they are required in the country and out of Kenya. The nursing council of Kenya is the regulatory body for nurses and midwives and has formulated a number of clinical assessments, which aim at assessing the clinical competence and clinical practice progress of the nurse student midwife. The assessments are carried out by two registered nurses from the school and the clinical practice site. The assessments tools are standardized and based on the competence based curriculum as provided by the nursing council of Kenya [3].

Midwifery education involves providing maternity care to a wide and diverse range of women, their babies, partners and families in a holistic way, where lifesaving skills are required by the student midwives [4]. The clinical practice component of nurse student midwives is core, in ensuring that student gain adequate hands on experience which translates to responsible, accountable, and independent professionals who can perform within the scope of professional practice [5]. The accompaniment of the student by faculty lecturers while in clinical practice training, is essential to guide and support student's apply the theoretical knowledge into actual health care provision [6]. The presences of the faculty lecturers during clinical practice training of nurse student midwives, reduces anxiety builds confidence among students, making them gain essential skills to provide safe and quality nursing care through real life practice and development of psychomotor skills. [7].

Clinical practice performance as the output variable in the study was constituted from the objective clinical assessments scores and the clinical progress report scores obtained during the entire clinical practice training period. Performance standards are described carefully and precisely to ensure that they contain all the key components of what is being assessed [output] and the criteria upon which assessments are based [6].

Clinical practice training provides opportunities for nurse student's midwives students to develop competence, as well challenge students' pre-conceived ideas about clinical practice, and assist them to develop perspectives on, and directions for their future careers as qualified nurse/midwives. Quality clinical practice training is one that successfully supports the student/learners achieve the aims of clinical education in the practice environment. It is aimed at providing quantity and quality learning that is supposed to be individualised to meet student needs, provide opportunities for skill development, socialisation into the profession, act as a bridge between academic and workplace learning and transform theory to practice, this happens when there is support from the team members in the clinical environment and faculty support [7-9].

In a study conducted among nurse student indicate that students do not integrate theory into practice because they lack adequate supervision during clinical practice training by faculty lecturers leading to low performance [9]. The attitudes of the instructors and mentors during clinical practice training can influence performance either positively or negatively among student nurse midwives. Constructive criticism improves practice in the clinical setting while negative criticism is an obstacle for effective clinical performance. Limited chance for hands on practice in training hospitals, shortage of nurse lecturers, clinical instructors, and too many students in the clinical practice sites competing for mothers can negatively affect performance during clinical practice training. Nursing/midwifery faculties should strive to choose practice sites with adequate learning opportunities for hands on experience.

Complexity of student clinical practice training performance postulates that adequate preparation for professional practice is core for health intervention to be adequately delivered to pregnant mothers. Despite consensus about the importance of the clinical learning experience, issues about the quality of the practice process persist with reports of complex problems surrounding the clinical practice experience, lack of active involvement of nursing and midwifery faculty in clinical learning of their student, accompanied by concerns about students' competence and confidence to practice and the outcome of performance [10].

Supervisory relationships have been reported by students as having direct effect on self-efficacy and learning outcomes. In studies conducted on the subject, students state that they want to spend their clinical practice training with knowledgeable and expert instructors for more effective learning. That instructor from the faculty may serve as an example for them since they have interacted with them in the classroom and are friendly and supportive for learning to be fully optimized. A study of nursing students demonstrated that the relationship between student satisfaction and a positive learning environment was bidirectional and had influence on how the student performed. The study also concluded that clinical learning should occur in environments designed for clinical education rather than offering services to ensure that the students acquire the necessary skills and satisfaction to promote good performance. [11, 2, 13]. 
The study [14] indicates that the learners in his study suggested improvement in clinical practice training. The main areas pointed at included supervision, monitoring clinical practice training of learners by faculty lecturers, having clear clinical objectives, timely feedback, learning without deadline pressure, talking about the expectations and challenges experienced, faculty planning learning schedules during clinical practice training, guidance, support, and innovation of learning activities are all deemed important in improving performance. A supportive culture during clinical practice training by lecturers and instructors offers students, the psychological safety necessary to ask and respond to questions, make and learn from mistakes, and initiate additional opportunities for learning. The excellence of any nursing and midwifery institution starts with the good performance of its students. This determines whether the goals of an institution can be achieved.

The clinical practice environment selected by the nursing and midwifery faculties may influence skill acquisition of learners. Clinical environment where the numbers of Caesarean -sections are higher, skills available for the student nurse midwives to learn and practice are limited hindering adequate skill acquisition through repetition. Clinical environment sites that are flexible in terms of letting student nurse have deliberate practice, makes the student gain experience more quickly than in sites that are not flexible. Mastery and skilful performance develop through participation in the social world, surrounded by others of shared interests and practice $[6,9,15]$.

The studies [12, 16] agrees that some procedures are considered high risk, and can only be performed by the doctors, making it difficult for students to practice such procedures which poses a challenge when they encounter these procedures as qualified midwives. A clinical learning environment that has a culture for quality and supports students learning, has been found to cultivate positive relationships, supports learning, and promotes best-practice in education and service delivery.

The studies $[17,18]$ indicate that the dramatic changes that may occur in midwifery to pregnant women and their babies, requires nurse student midwives to learn and utilize management skills in the clinical field appropriately. It is the duty of the clinical instructors and faculty lecturers to teach assess the students for mastery of skills. A study on problems of nurse lecturers while instructing student midwives established that the performance of student was dependent on the clinical interest in mentoring. Student in this study were in agreement that clinical instructors positive attitudes enhanced their learning. The willingness of the clinical instructors to communicate, support and guide them as well as encouraging them to engage in new learning activities enhanced skill development and performance. The clinical instructors/lecturers are required to demonstrate clinical expertise that includes current and efficient midwifery practice.

Students tend to characterize effective supervision and support to include a consistent approach where the class instructor/lecturer is available; more routine supervision sessions, balanced with feedback and fair transparent assessment processes and a respectful judgment, free relationship leading to good learning outcome and clinical practice performance. The aim of this paper was to examine faculty support towards student nurse midwives performance during midwifery clinical practice at Kenya Medical Training Colleges in the selected Counties in Kenya.

\section{Methodology}

\subsection{Study Design}

Descriptive analytical study utilizing mixed methods both qualitative and quantitative data. This study utilized the analytical means to provide information on the positive and negative factors that determine student nurse midwives performance during midwifery clinical practice training in respect to the nursing faculty support.

\subsection{Study Setting}

The study was conducted at Kenya medical training college, and its constituent colleges in 8 regions in Kenya. The regions were purposely selected for the study, though once in the region systemic sampling method was adopted to select one nursing campus to be included in the study. There are about 47 constituent colleges training nursing and midwifery. Kenya Medical Training College was established 1927 to train mid-level health professionals and is the largest training institution, that releases registered nurse/ midwives to the job market. Every year an estimated 5,000 nurse midwives students qualify from the 47 constituent colleges. Kenya Medical Training College boarders Kenyatta national Referral Hospital and the Faculty of Medicine University of Nairobi. The vision of the College is to be a model institution in training and development of competent health care professionals who are responsive to the needs of the community they serve.

\subsection{Study Population}

The study population comprised of final year Kenya Registered Community Health Nursing students, who were in their final midwifery clinical placements. These students were accessed through a sampling frame of the entire final year nursing students from the 25 constituent colleges, and this information was obtained from the college admissions department. The final year student were chosen because they had covered their entire midwifery clinical placement which is 36 weeks, and were in the final placement and a more probable time to gauge their performance before they are deployed to various clinical sites. The clinical instructors directly involved in mentoring the students, formed the key informants interview group that gave views and opinions on the determinants of student performance during midwifery clinical placement. Any final year student not undertaking the three and half basic programme and not willing to consent to participate in the study was left out. 


\subsection{Sample Size}

The sample size was composed of 301 nurse student from various colleges. Furthermore, the 301 students were divided, among the 8 nursing colleges selected per province, which translated to 38 students from each college. Those who consented were included in the study. Confidentiality was maintained throughout the study.

\subsection{Data Collection}

Data collection methods included use, of a structured questionnaire, focus group discussion with student nurse midwives, and key informant interview with the clinical instructors.

\section{Results}

\subsection{Demographic Characteristics of the Participants}

A total of 291 final year nurse students undertaking midwifery course were recruited into the study from 8 KMTC colleges.

Table 1. Demographic characteristics of final year nurse midwives students at KMTC.

\begin{tabular}{lll}
\hline & Frequency [n] & Percent [\%] \\
\hline Sex & & \\
Male & 103 & $35.4 \%$ \\
Female & 188 & $64.6 \%$ \\
Age in years & & \\
$20-23$ & 142 & $48.8 \%$ \\
$24-27$ & 116 & $39.9 \%$ \\
28 and above & 3 & $11.3 \%$ \\
Religion & & \\
Christian & 246 & $84.5 \%$ \\
Muslim & 25 & $8.6 \%$ \\
\hline
\end{tabular}

\begin{tabular}{lll}
\hline Marital status & & \\
Married & 31 & $10.7 \%$ \\
Single & 260 & $89.3 \%$ \\
Total & 291 & 100.0 \\
\hline
\end{tabular}

\subsection{Gender Distribution}

Females accounted for $64.6 \%$ of the participants yielding a ratio of male-to-female students of approximately 1:2 among nurse midwifery students.

\subsection{Age Distribution}

The mean age of the students was 22.3 years [SD 2.4]. The modal age group was 20-23 years; 142 [48.8\%] students were in the age range of $20-23$ while 116 [39.9\%] were in the age bracket of 24-27.

\subsection{Religion}

Christians were $84.8 \%$ and Muslims $15.2 \%$. There were slightly more male Christians, 86.3 compared to females [84.0\%].

\subsection{Marital Status}

Only $10.7 \%$ of the students were married while the rest $89.3 \%$ were single. The distribution of marital status with respect to gender was $5.9 \%$ of the males compared to $13.4 \%$ of females were married with the difference attaining borderline statistical significance, $\mathrm{P}=0.049$.

\subsection{Entry Grade}

110 [37.8\%] of the students had scored B- and above and $181[52.2 \%]$ scores grade $\mathrm{C}$ and $\mathrm{C}+$.

\subsection{Faculty Support Analysis}

Table 2. Faculty support analysis.

\begin{tabular}{|c|c|c|c|c|c|}
\hline & \multicolumn{2}{|c|}{ Faculty support [7 Likert items] } & \multirow{2}{*}{ Total } & \multirow{2}{*}{ Chi square } & \multirow{2}{*}{$P$ value } \\
\hline & Good support $[<70 \%]$ & Poor support $[\geq 70 \%]$ & & & \\
\hline \multicolumn{6}{|c|}{ Performance based on progress report } \\
\hline Good [65\% and above] & $55[73.3]$ & $109[50.5]$ & $164[56.4]$ & 1.2 & 0.276 \\
\hline Poor $[64 \%$ or below $]$ & $20[22.7]$ & $107[49.5]$ & $127[43.6]$ & & \\
\hline Total & $75[100]$ & $216[100]$ & $291[100]$ & & \\
\hline \multicolumn{6}{|c|}{ Performance based on clinical assessment } \\
\hline Good [65\% and above] & $40[83.3]$ & $185[76.1]$ & $225[77.3]$ & 17.0 & $<0.001$ \\
\hline Poor $[64 \%$ or below $]$ & $8[16.7]$ & $58[23.9]$ & $66[22.7]$ & & \\
\hline Total & $48[100]$ & $243[100]$ & $291[100]$ & & \\
\hline
\end{tabular}

Faculty support was measured using an index calculated from responses to seven likert scale items [range 5-35] with a score of $70 \%$ and above representing good support by faculty. Good faculty support was significantly associated with good performance in clinical assessment $[83.3 \%$ versus $76.1 \% ; \mathrm{p}<0.001]$. However, there was no significant association between progress report scores and faculty support [73.3\% versus $50.5 \% ; \mathrm{p}=0.276]$.

The Likert scale items used to gauge faculty support are presented below. Poor faculty support was noted in four areas: guided reflection at $27.1 \%$, regular contact of clinical staff and lecturers to discuss performance $10.6 \%$, timely and regular feedback $24.2 \%$ and action when performance falls to unacceptable levels at $35.3 \%$. 


\subsection{Likert Scale for Gauging Faculty Support}

Table 3. Likert scale used to gauge faculty support.

\begin{tabular}{|c|c|c|c|}
\hline \multirow{2}{*}{\multicolumn{2}{|c|}{ Parameters }} & \multicolumn{2}{|c|}{ Level of support\% } \\
\hline & & \multirow{2}{*}{$\begin{array}{l}\text { Good support } \\
27.1\end{array}$} & \multirow{2}{*}{$\begin{array}{ll}\text { Poor support } \\
70.7\end{array}$} \\
\hline 3.1 & Guided reflection on clinical practice with faculty lecturers supported and promoted good performance. & & \\
\hline 3.2 & $\begin{array}{l}\text { Regular contact between clinical instructors, faculty lecturers and student to discuss gaps and challenges, } \\
\text { promoted good performance. }\end{array}$ & 10.6 & 83.7 \\
\hline 3.3 & $\begin{array}{l}\text { Faculty lecturer secured appropriate clinical sites with adequate learning opportunities enhancing skill } \\
\text { development and good performance }\end{array}$ & 68.6 & 24.8 \\
\hline 3.4 & $\begin{array}{l}\text { Regular supervision and timely feedback on clinical practice performance enhanced corrective measures and } \\
\text { higher achievement }\end{array}$ & 24.2 & 72.1 \\
\hline 3.5 & $\begin{array}{l}\text { Clinical objectives to be achieved in each clinical practice were prepared in advance to ensure that clinical } \\
\text { practice was more focussed. }\end{array}$ & 63.5 & 26.6 \\
\hline 3.6 & Theory - practice gap affected my performance during midwifery clinical practice & 57.4 & 41.2 \\
\hline & $\begin{array}{l}\text { Action was taken immediately by lecturers during clinical practice when student performance was below } \\
\text { unacceptable standards }\end{array}$ & 35.3 & 57.7 \\
\hline
\end{tabular}

From Table 3 above indicates how the Likert scale was used for gauging the Faculty support at various levels with $68.6 \%$ citing that lecturers secured appropriate clinical sites with adequate learning opportunities enhancing skill development and good performance.

\subsection{Frequencies of Clinical Visits by Lecturers to Evaluate Performance}

Table 4. Clinical visits by lecturers to evaluate performance.

\begin{tabular}{lll}
\hline Frequency of lecturers visit to clinical site to evaluate performance & Frequency & Percent \\
\hline At beginning of placement & 32 & 11.0 \\
Frequently to assess student challenges \& progress & 19 & 6.5 \\
At end of placement for practical assessment & 240 & 82.5 \\
Total & 291 & 100.0 \\
\hline
\end{tabular}

The above Table 4 indicated that 240 [82.5\%. were visited at end of placement, 32 [22\%] at the beginning with only 19 $[27.5 \%]$ indicated being frequently visited by the lecturers.

Table 5. The lecturer's role during clinical practice visit.

\begin{tabular}{lll}
\hline Lecturer's role during clinical visit & Frequency & Percent \\
\hline Clinical teaching & 35 & 12.0 \\
Clinical assessment & 220 & 75.6 \\
Clinical supervision & 36 & 12.4 \\
Total & 291 & 100.0 \\
\hline
\end{tabular}

The findings from Table 5 above shows that the majority of the participants indicated that the lecturer role during the clinical visits was assessments which accounted for 220 (75.6\%), clinical supervision was $36(12.4 \%)$ and $35(12 \%)$ were of the view that their role was clinical teaching.

\section{Discussion}

The findings of the study revealed that Good faculty support was significantly associated with good performance in clinical assessment (83.3\% versus $76.1 \%$; p $<0.001)$. However, there was no significant association between progress report scores and faculty support $(73.3 \%$ versus $50.5 \% ; \mathrm{p}=0.276$ ) through the trends of progress reports indicated that there was good support. The findings of this study are in agreement with the research by [19] whose study established that when lecturers spend at least one day, per week supporting and instructing students and helping them gain competencies during clinical training practice, would enhance them to acquire the necessary skills leading to good performance. Supervision and providing timely feedback was found to be the core business of the lecturers, to enable learners to be aware of what is expected of them expected of them and become socialized with the realities of clinical practice and their roles as qualified professional midwives. The study by [19] emphasis that clinical practice requires a commitment of lecturer who guide, coach and provide timely feedback to nurse students on their performance, for effective student competence or learning in clinical areas.

This particular study established that students were not supported by the faculty in terms of learning opportunities sought.

One student lamented

The clinical sites are so congested with student from all over other institutions, and the students are more than the mothers to deliver. That is why the lecturers should accompany us and teach us in such circumstances. Lamentation from male student.

The study concurs with [6] whose study established that clinical settings was the best place to learn, but the 
experience opportunities were not always available for every skill for the nurse student midwives. Lack of active participation in direct patient care such conducting delivery of mothers impede student development and confidence. The clinical practice site identified the faculty should increase student participation characterized by experiences of mothers/client/patients in their entirety, promoting initiative, confidence, learning, and understanding of the professional role that is ahead of them.

Sometimes the lecturer only visits the clinical environment a week to the final clinical assessment, to introduce him or herself and request the in charge to provide a co-assessor. This is ridiculous.

The study [20] concurs that the type of support that students receive during clinical practice influences educational outcomes. He also reported that the intentions that are supportive will always significantly affect academic performance. He continues to say that, the type of support student receive influence learning and teaching in the way content is organized and the assessment procedures.

Most of the time the doctor is the one to conduct vaginal examination during the routine round. The student only observes, and since policy dictates that $V$. $E$ is done 4 hourly, then the student does not have a chance. These are the challenges that we want our lecturers to accompany us during clinical practice and observe.

Midwifery lecturers ought, to ensure that obstacles that lead to dissatisfaction during clinical practice are addressed through adequate and effective supervision. Giving student's patient assignment and case presentations of clinical cases could help reduce anxiety and fear of making mistakes. The collaboration between the nursing and midwifery faculty lecturers and the clinical environment staff is essential, to identify challenges that student encounter during clinical practice. It is the responsibility of the faculty of nursing and midwifery to deal with factors that interfere with good clinical practice performance, for the nurse student midwives to acquire all the necessary competences to become socialized with their professional roles as future midwives [4, 21].

Lecturers need to take up responsibility of teaching student during clinical placement, there is no way student can gain skills if they are left alone even for up to three months without lecturers, visiting to see if we are meeting the clinical objectives or not." It's bad to assess us at the end of placement, when we really did not learn, because everyone in the clinical environment is busy and no one to teach you, you observe the shortcuts and this is what you will do when you qualify.

The findings in Table 5 gives a clear picture that lecturers role during midwifery clinical practice in this study was more evaluative, with $83 \%$ respondents lamenting that lecturers only visited clinical practice site at the end of practice for clinical practice assessments $76 \%$.

The studies $[4,9,22]$ clearly states that there is need for lecturers to have more contacts with the students during clinical practice to ensure that clinical performance learning is optimized. Studies have shown that constant faculty involvement in clinical teaching and adequate supervision of students during practice significantly increased their feeling of satisfaction with clinical practice. This raises serious concern that midwifery being a practice profession is taught by faculty with limited contact with clinical practice settings.

Another student responded:

I agree that support seeking is key, but the lecturers teach theory and remain in school, and are nowhere to see what we are doing in the clinical environment for consultation.

In consistent to the findings of this study, numerous studies have established that faculty lecturers do not routinely supervise learners, neither follow them during clinical practice training. It is recommended that clinical training of students nurse midwives must be based on realities in health care, and non-involvement of nursing/midwifery faculty lecturers in clinical training is potentially injurious to midwifery education and the graduates' performance in practice, which may translate to poor health of the pregnant mother and the unborn babies and increase in maternal mortality rate.

In this study the majority of students had the perception that their lecturers had a more evaluative role than a teaching role.

it very unfair when the faculty lecturer appears on the day of the practical assessments and fails you, insisting that you didn't conduct the delivery appropriately, or did not deliver the placenta according to active management of third stage yet, she the never visited you during the entire placement to tell you how to deliver the placenta to control bleeding or how to support the head during delivery. 27 year old female student said.

This calls for the nursing lecturers to accompany their students during midwifery clinical practice, to teach best practices in midwifery. Having a team of supervisors/lecturers during clinical practice training, is appreciated by the students as it enhances the students' thinking and reflecting on patient care and on their own learning, as well as further developing their existing knowledge and skills [24].

We were taught many complicated deliveries in class, but the realities in clinical learning environment, is that these are procedures labelled for doctor only in some sites vagina examination are done only by doctors. How do they expect the student to learn? 24 year old student lamented.

Another student said

Some clinical learning environments are mainly dealing with elective caesarean /section, and students have no delivery catches. This is particular in referral clinical environment. The findings collaborate with studies done by other scholars that considered some deliveries high risk and can only be performed by medical doctors and this is outlined by the policies of the hospitals. This calls for nursing and midwifery faculties to select clinical learning environment with adequate learning experiences for deliberate practice of student nurse midwives.

The conclusion of the study based on the results, indicate 
that clinical practice training performance of student nurse midwives was influenced by faculty support in terms of clinical teaching, accompaniment of student nurse midwives and unsupportive policies and procedures during clinical practice training. The results from the focussed group discussion students suggested that links with the nursing faculty lecturers whilst they were in practice may help integrate theory and practice and gave examples where they had benefited from the opportunity when the faculty lecturers visited the clinical site to demonstrate how to conduct a delivery and for reflective sessions. Consistent with other research [23] indicate that clinical environment support will enable student develop competencies and improve perceptions of their self-worth and value, resulting to good clinical practice performance.

\section{Conclusion}

The findings of this study clearly indicate that the level of nursing faculty support of nurse student midwives, during midwifery clinical practice training, among the selected nursing and midwifery institutions at Kenya Medical Training College was inadequate.

The factors that influenced good performance during clinical practice training included; facilitative supervision in terms of clinical teaching, guidance and timely constructive feedback, accompaniment of nurse student midwife by lecturers, to identify challenges and causes of stress and anxiety, Availability of diverse learning opportunities to enhance psychomotor skill acquisition, policies and procedures of clinical practice environment, that prevented hands on experience for some procedures were identified as determinates of good performance during midwifery clinical practice training.

The student viewed the lecturer role during clinical practice training as more evaluative than supportive in terms of practicing best practices and maximizing the learning experiences. The theory practice gap was a major concern by the students which could be bridged with adequate support of student by the faculty lecturers.

\section{Recommendations}

1. Nursing and Midwifery Faculty should support good performance of students by lecturers accompanying nurse student midwives during clinical practice training and supporting them through clinical teaching. This underlies the importance of considering these factors during training of student nurse midwives to ensure that clinical learning is optimized.

2. There is need for Faculties of Nursing to plan, the midwifery curriculum in a way that nursing students be involved actively in their education, by ensuring that student are placed in clinical sites that are not congested, and where mothers are adequate, for them to have hands on learning opportunities to gain experience and practice the skills adequately.

\section{Acknowledgements}

My sincere gratitude goes to my two supervisors Dr. Omuga and Leila Geteri for the continuous guidance and timely constructive comments. Dr Philip Ayieko of Welcome KEMRI for his assistance with the statistical analysis of the data. My gratitude is extended to the director Kenya Medical Training College for giving me a chance to conduct the research in the nursing colleges. I express my gratitude to the authorities of the selected nursing schools and hospitals for granting me the permission to collect data for this study.

\section{References}

[1] Nursing \& Midwifery Council. (2018). the code: Professional standards of practice and behaviour for nurses, midwives and nursing associates. Retrieved from http://www.nmc.org.uk/globalassets/sitedocuments/nmcpublications/revised-new-nmc-code.pdf.

[2] Hoy G, George S (2018) New standards on the supervision and assessment of students in practice. Nursing Times [online]; 114: 12, 27-29.

[3] NCK [2018]. Kenya registered community health nursing (Basic) Training Guidelines revised Edition, Goverment press, Nairobi, Kenya.

[4] M. Dehghani, Ghanavati S., Soltani B. et al., "Impact of clinical supervision on field training of nursing students at Urmia University of Medical Sciences," Journal of Advances in Medical Education \& Professionalism, vol. 4, no. 2, pp. 8892, 2016. View at Google Scholar.

[5] International Confederation of Midwives [2010] Global Standards for Midwifery Education. Availableat: http://www.internationalmidwives.org/Policyandpractice/ICM Global Standards Competencies and Tools/Global Standards English/tabid/980/Default.aspx [Last accessed].

[6] Hussein MH, Osuji J. Bridging the theory-practice dichotomy in nursing: The role of nurse educators. J Nurs Educ Pract 2017; 7 (3): 20-5.

[7] J. Lawal, S. Weaver, V. Bryan, and J. L. Lindo, "Factors that influence the clinical learning experience of nursing students at a Caribbean school of nursing," Journal of Nursing Education and Practice, vol. 6, no. 4, p. 32, 2015. View at Publisher View at Google Scholar.

[8] L. Rajeswaran, "Clinical experiences of nursing students at a selected institute of health sciences in Botswana," Health Science Journal, vol. 10, no. 6, 2017. View at Publisher · View at Google Scholar.

[9] M. Birks, T. Bagley, T. Park, C. Burkot, and J. Mills, "The impact of clinical placement model on learning in nursing: A descriptive exploratory study," Australian Journal of Advanced Nursing, vol. 34, no. 3, pp. 16-23, 2017. View at Google Scholar View at Scopus.

[10] L. N. Pinehas, E. Mulenga, and J. Amadhila, "Factors that hinder the academic performance of the nursing students who registered as first years in 2010 at the University of Namibia (UNAM), Oshakati Campus in Oshana, Namibia," Journal of Nursing Education and Practice, vol. 7, no. 8, p. 63, 2017. View at Publisher View at Google Scholar. 
[11] Z. C. Chan, C. Tonga, and S. Henderson, "Power dynamics in the student-teacher relationship in clinical settings," Nurse Education Today, vol 49, pp. 174-179, 2017.

[12] Margaret Maura Mcallister, [2012]. Challenges facing nursing education in Australia: Two solutions, journal of nursing education and practice. Vol 2 [1]: 23-26. $2^{\text {nd }}$ edition, sciedu press. Australia.

[13] E. A. Flott and L. Linden, "The clinical learning environment in nursing education: a concept analysis," Journal of Advanced Nursing, vol. 72, pp. 501-513, 2016.

[14] Safazadeh S, Irajpour A, Alimohammadi N, Haghani F. Bridging the theory-practice gap in Iranian emergency nursing education. ARYA Atheroscler 2018; 14 (3): 105-14.

[15] Jansson I, Ene KW. Nursing students' evaluation of quality indicators during learning in clinical practice. Nurse Educ Pract 2016; 20: 17-22.

[16] Beverley Y. Learning nursing: Gaining an insight into what helps students to make sense of nursing knowledge and practice $[\mathrm{PhD}$ Thesis]. Glasgow, UK: University of Strathclyde; 2015.

[17] Nasrin, E. Fatemeh, A. and Fazlollah, A. [2013]. Effectiveness education: A content analysis of key experiences of teachers' about quality of evaluation and applied knowledge in nursing education. Acad. J. Edu Res. 1 [1]: 001-007.

[18] Vivian, E. A., Mary, B. S., Antanga, J. A. and Gibson, D.
[2011]. Nurses and Challenges faced as clinical educators. A survey of a group of nurses in Cameroon. Pan African Medical journal Research, VOL. 8, No. 28.

[19] Hayan, I. A. and Azza, H. E. [2011]. "A qualitatative study of effectiveness of clinical teaching. A journal of American science", Vol. 29 PP179-182.

[20] O'Donovan A, Halford W, Walters, B. [2011]. Towards best practice supervision of clinical psychology trainees. Australian Psychologist 46 [2]: 101-112.

[21] K. A. Abrahamson, R. L. Fox, and B. N. Doebbeling, "Facilitators and barriers to clinical practice guideline use among nurses," AJN The American Journal of Nursing, vol. 112, no. 7, pp. 26-35, 2012. View at Google Scholar.

[22] Walker S, Dwyer T, Moxham L, Broadbent M, Sander T. Facilitator versus preceptor: which offers the best support to undergraduate nursing students? Nurse Educ Today. 2013; 33: $530-5$.

[23] Rodger, S. Fitzgerald, C. Davila, W. Millar, F. Allison, H. [2011]. What makes a quality occupational therapy practice placement? Students' and practice educators' perspectives. Australian Occupational Therapy Journal 58 [20]: 195-202.

[24] Henderson A, Eaton E. Assisting nurses to facilitate student and new graduate learning in practice settings: What "support" do nurses at the bedside need? Nurse Educ Today. 2013; 13: 197-201. 